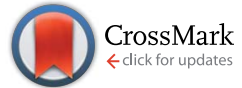

Cite this: J. Mater. Chem. A, 2014, 2 , 12630

Received 30th January 2014 Accepted 26th March 2014

DOI: $10.1039 / c 4 t a 00546 \mathrm{e}$

www.rsc.org/MaterialsA

\section{Effects of the La/W ratio and doping on the structure, defect structure, stability and functional properties of proton-conducting lanthanum tungstate $\mathrm{La}_{28-x} \mathrm{~W}_{4+x} \mathrm{O}_{54+\delta}$. A review}

\begin{abstract}
Anna Magrasó* and Reidar Haugsrud
The present review focuses on characteristics of lanthanum tungstate in the compositional region 25-30 mol\% $\mathrm{La}_{2} \mathrm{O}_{3}$ in the $\mathrm{La}_{2} \mathrm{O}_{3}-\mathrm{WO}_{3}$ phase diagram. These tungstates represent an interesting family of materials for technological applications being proton or mixed proton-electron conductors depending on conditions. The material family was traditionally identified as $\mathrm{La}_{6} \mathrm{WO}_{12}$. However, recent efforts have shown that lanthanum tungstate can more correctly be represented by the formula $\mathrm{La}_{28-x} \mathrm{~W}_{4+x} \mathrm{O}_{54+\delta}$, where nearly one tungsten $(x \sim 1)$ dissolves in lanthanum sites to form a stable composition. In the present contribution, the importance of the crystal structure and the effect of the La/W ratio on stability, defect chemistry and, accordingly, transport properties of this material are reviewed. A revisited phase diagram in this compositional region is presented. Reported doping strategies on both the A- and B-sites are discussed in view of the applicability of these materials as dense ceramic $\mathrm{H}_{2}$ separation membranes.
\end{abstract}

\section{Stoichiometry, chemical formula, and phase diagram}

Early works on rare-earth tungstates (" $\mathrm{Ln}_{6} \mathrm{WO}_{12}$ ") were carried out in the $60 \mathrm{~s}$ and $70 \mathrm{~s}$ by various researchers, ${ }^{1-9}$ where the chemical formula originated from an older nomenclature

Department of Chemistry, University of Oslo, Centre for Materials Science and Nanotechnology (SMN), FERMiO, Gaustadalléen 21, NO-0349, Oslo, Norway. E-mail: a.m.sola@smn.uio.no; annamagraso@gmail.com; Fax: +47-22840651; Tel: $+47-22840660$

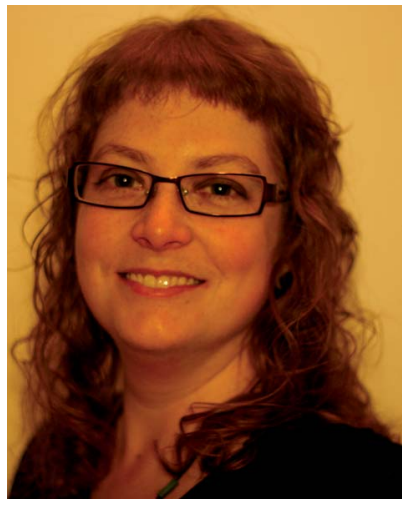

Anna Magrasó obtained her PhD degree in Materials Technology at the University of Barcelona in 2007. She has been working as a postdoctoral researcher at the University of Oslo during 20082014, and has specialised in the field of oxide ceramics for high temperature solid-state proton conductors. She focused on the development of new materials for use in proton conducting fuel cells or dense $\mathrm{H}_{2}$ permeable membranes and its fundamental understanding. She is currently moving to the Catalan Institute of Nanoscience and Nanotechnology (Spain). expressing the proportion of the parent oxides, i.e. $\mathrm{Ln}_{2} \mathrm{O}_{3}: \mathrm{WO}_{3}=3: 1$. This nomenclature has also been widely used for isostructural materials, such as rhenates, uranates and molybdates, generally written as $\mathrm{Ln}_{6} \mathrm{MO}_{12}$, where $\mathrm{Ln}$ is a rare earth element or $\mathrm{Y}$, and $\mathrm{M}=\mathrm{Mo}, \mathrm{U}$ or Re. ${ }^{\mathbf{1 , 1 0 - 1 2}}$ This has led to confusion regarding the actual chemical formula of lanthanum tungstate (and likely for other tungstates with large rare-earth cations), and to an incorrect range of the $\mathrm{La} / \mathrm{W}$ ratio with single phase compositions, as argued in the following. Some researchers initially claimed that " $\mathrm{La}_{6} \mathrm{WO}_{12}$ " was a single phase material after annealing powders prepared by traditional solid

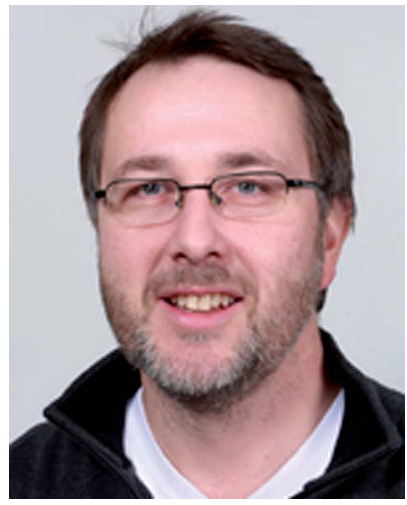

Reidar Haugsrud is a Associate Professor at Department of Chemistry, University of Oslo (UiO). His scientific focus is on defect chemistry and transport of functional oxides for energy technology. Haugsrud graduated as a doctor in inorganic chemistry at UiO in 1999 with a thesis on the corrosion mechanism for metals and single and multi-phase alloys. Since 2002, his main contributions have been on the development and understanding of new materials for solid oxide fuel cells and ceramic gas separation membranes. 
Table 1 List of the most common nomenclatures for lanthanum tungstate, all referring to the same material

\begin{tabular}{llllll}
\hline Acronym & La/W ratio & 1 & 2 & 3 & 4 \\
\hline LWO60 & 6 & $\mathrm{La}_{6} \mathrm{WO}_{12}$ & $3: 1 \mathrm{La}_{2} \mathrm{O}_{3}: \mathrm{WO}_{3}$ & $\mathrm{LaW}_{1 / 6} \mathrm{O}_{2}$ & $\mathrm{La}_{6} \mathrm{WO}_{12}$ \\
LWO54 & 5.4 & - & - & - & $\mathrm{La}_{5.4} \mathrm{WO}_{12-\delta}$ \\
$\mathrm{La}_{5} \mathrm{WO}_{12-\delta}$ & $-\mathrm{La}_{27} \mathrm{~W}_{5} \mathrm{O}_{55.5}{ }^{a}$ \\
${ }^{a} \mathrm{La}_{28-x} \mathrm{~W}_{4+x} \mathrm{O}_{54+\delta}, x=1$. & 5.0 & $\mathrm{La}_{10} \mathrm{~W}_{2} \mathrm{O}_{21}$ & $5: 2 \mathrm{La}_{2} \mathrm{O}_{3}: \mathrm{WO}_{3}$ & - & \\
\end{tabular}

state reaction at $\sim 1400{ }^{\circ} \mathrm{C} .{ }^{8}$ However, when Chang and Phillips ${ }^{7}$ indexed the XRD patterns of " $\mathrm{La}_{6} \mathrm{WO}_{12}$ " according to a fluoriterelated structure, two additional reflections were present, more recently identified as $\mathrm{La}_{2} \mathrm{O}_{3} \cdot{ }^{13}$ Yoshimura and Rouanet ${ }^{9}$ studied the phase diagram of the $\mathrm{La}_{2} \mathrm{O}_{3}-\mathrm{WO}_{3}$ system in more detail based on rapid quenching of oxide melts (see Fig. 1a, re-drawn by Chambrier et $\left.a l^{14}\right)$. They observed that $\mathrm{La}_{6} \mathrm{WO}_{12}$ is not thermodynamically stable below $1740{ }^{\circ} \mathrm{C},{ }^{,, 15}$ but rather that a more tungsten rich phase, $\mathrm{La}_{10} \mathrm{~W}_{2} \mathrm{O}_{21}$ (also written as $\mathrm{La}_{2} \mathrm{O}_{3}: \mathrm{WO}_{3}=5: 2$ ), forms below this temperature. Due to the numerous ways of reporting the chemical formula of lanthanum tungstate (summarized in Table 1) it is convenient to use the La/W ratio to avoid misperception, as they all refer to the same material with small variations in the cation ratio. The compositions will be labeled as LWO $x$, where $x$ represents the nominal La/W ratio multiplied by 10 .

Recently, Magrasó et al. ${ }^{13}$ have shown that neither LWO60 (" $\mathrm{La}_{6} \mathrm{WO}_{12}$ ") nor LWO50 (" $\mathrm{La}_{10} \mathrm{~W}_{2} \mathrm{O}_{21}$ ") are single phase materials after firing freeze dried powders at temperatures in the range of $1300-1500{ }^{\circ} \mathrm{C}$. In addition to the fluorite-related material forming for both compositions, $\mathrm{La} / \mathrm{W}=6$ yields $\mathrm{La}_{2} \mathrm{O}_{3}$ segregation while for $\mathrm{La} / \mathrm{W}=5$, a $\mathrm{W}$-rich phase identified as $\mathrm{La}_{6} \mathrm{~W}_{2} \mathrm{O}_{15}$ was formed. Later, other laboratories have independently confirmed that LWO60 and LWO50 are not single phase materials also when using conventional solid state synthesis methods ${ }^{16,17}$ at temperatures below $1500-1600{ }^{\circ} \mathrm{C}$. Recently, ${ }^{18}$ it was stated that the previous chemical formulae considered as two different compositions ( $\mathrm{La}_{6} \mathrm{WO}_{12}$ " or " $\mathrm{La}_{10} \mathrm{~W}_{2} \mathrm{O}_{21}$ ") refer to the same material (both containing segregations), and may be seen as a simplification of a more complex formula: $\mathrm{La}_{28-x} \mathrm{~W}_{4+x} \mathrm{O}_{54+3 x / 2}$ (LWO). ${ }^{19}$ Indeed, the powder data files available for " $\mathrm{La}_{6} \mathrm{WO}_{12}$ " (pdf: 30-0687, $a=11.179 \AA$ ) and " $\mathrm{La}_{10} \mathrm{~W}_{2} \mathrm{O}_{21}$ " (pdf: 30-0686, $a=11.167 \AA$ ) reveal that the number of reflections and their intensities are essentially equal, with only a small difference in the lattice parameters.

From the data available in ref. 13, a new phase diagram was constructed in the region $6 \geq \mathrm{La} / \mathrm{W} \geq 4.8$ (Fig. $1 \mathrm{~b}$ ) at temperatures of $1000-1600{ }^{\circ} \mathrm{C}$. Important to note from this diagram is firstly that there is a solid solution where the cubic fluoriterelated phase $\left(\mathrm{La}_{28-x} \mathrm{~W}_{4+x} \mathrm{O}_{54+3 x / 2}, x \sim 1\right)$ is identified. This can be concluded since there are no apparent differences in the number of peaks (from XRD) or their relative intensity, meanwhile the lattice parameter changes continuously as a function of La/W ratio (Fig. 2). Secondly, the composition range where LWO is a single phase material, depends on the temperature. This reflects that the solubility of tungsten in La2 sites ( $x$ in $\mathrm{La}_{28-x} \mathrm{~W}_{4+x} \mathrm{O}_{54+3 x / 2}$ ) varies with temperature. Thirdly, if the solid solubility range is extrapolated to temperatures above $1600{ }^{\circ} \mathrm{C}$
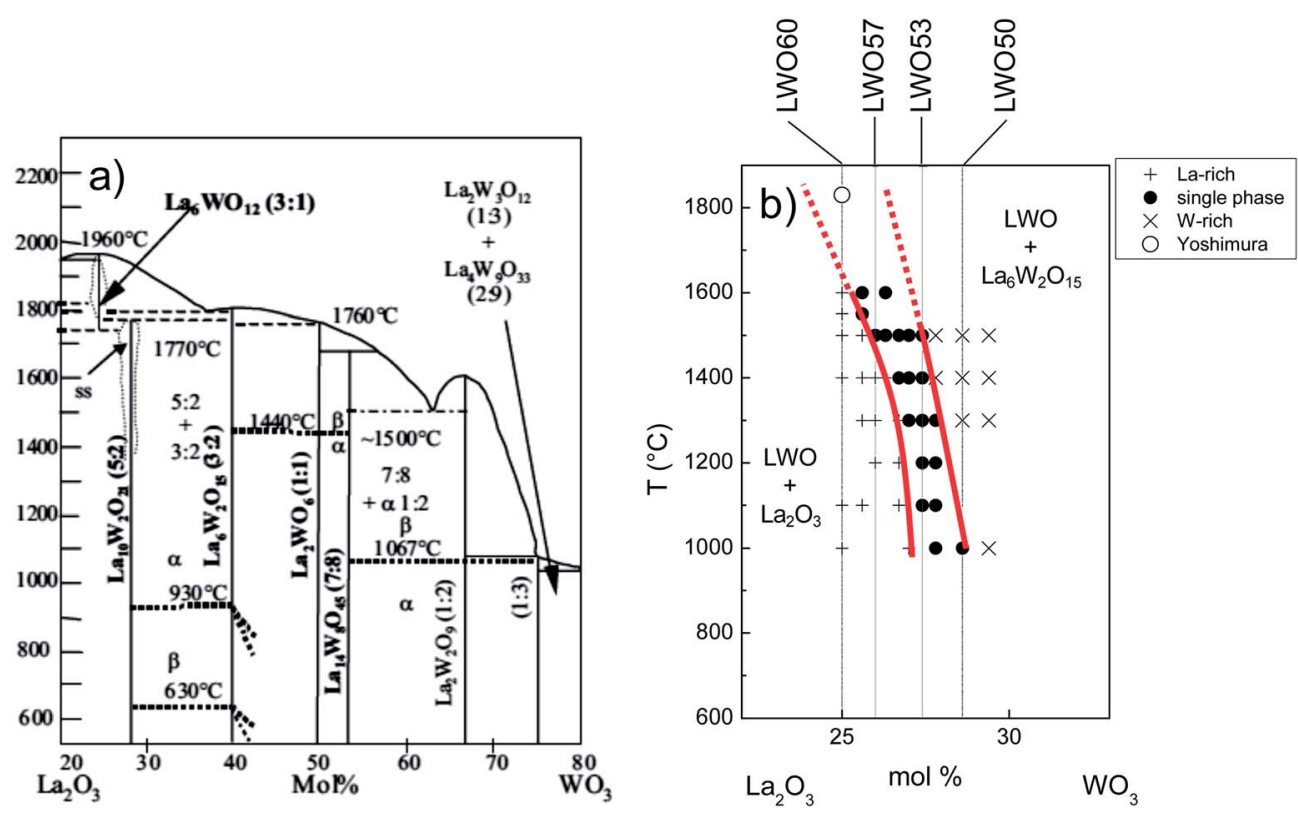

Fig. 1 (a) Phase diagram by Yoshimura and Rouanet, ${ }^{9}$ re-drawn by Chambrier et al. ${ }^{14}$ (b) Revised $\mathrm{La}_{2} \mathrm{O}_{3}-\mathrm{WO}_{3}$ phase diagram based on the data extracted from ref. 13. The dotted lines have been hypothetically extrapolated. 


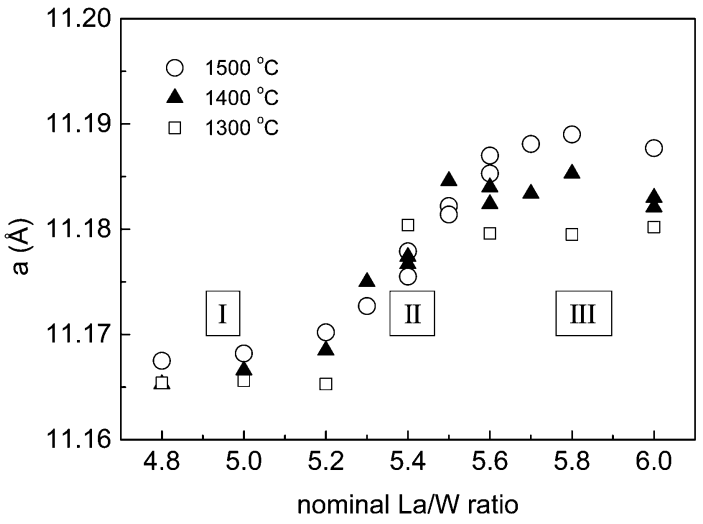

Fig. 2 Variation of the lattice parameter obtained by XRD as a function of the nominal La/W ratio after firing at 1300,1400 or $1500{ }^{\circ} \mathrm{C}$.

(dotted lines in Fig. 1b) the composition written by Yoshimura and Rouanet ${ }^{9}$ as " $\mathrm{La}_{6} \mathrm{WO}_{12}$ " reported to be stable above $1740^{\circ} \mathrm{C}$, indeed falls inside the single phase region. It is interesting to note from the phase diagram reported by Yoshimura and Rouanet ( $c f$., Fig. 1a) $)^{9}$ that the two undefined high temperature regions present around $\mathrm{La}_{10} \mathrm{~W}_{2} \mathrm{O}_{21}$ and $\mathrm{La}_{6} \mathrm{WO}_{12}$ correspond to one single solid solution region, as shown in Fig. $1 \mathrm{~b}$.

Fig. 2 shows the variation of the lattice parameter as a function of the nominal $\mathrm{La} / \mathrm{W}$ ratio derived from XRD after firing the different compositions at 1300,1400 or $1500{ }^{\circ} \mathrm{C}$. As reported previously, ${ }^{13}$ there are three distinguishable regions. In region I (low $\mathrm{La} / \mathrm{W}$ ratio) and region III (high $\mathrm{La} / \mathrm{W}$ ratio) the lattice parameter is virtually independent of the $\mathrm{La} / \mathrm{W}$ ratio (though dependent on the firing temperature), and XRD patterns show segregation of $\mathrm{La}_{6} \mathrm{~W}_{2} \mathrm{O}_{15}$ or $\mathrm{La}_{2} \mathrm{O}_{3}$ phases, respectively. In region II the patterns show only the single phase and the lattice parameters increase with increasing lanthanum content, following a linear behavior. The La/W-composition range of region II depends on the firing temperature, well in accordance with the phase diagram shown in Fig. 1b. At lower firing temperatures, the lattice parameters level off at lower values, which indicates that the LWO phase contains a lower La/ $\mathrm{W}$ ratio compared to higher temperatures. At $1500{ }^{\circ} \mathrm{C}$, LWO is a single phase material for $5.7 \geq \mathrm{La} / \mathrm{W} \geq 5.3$, and the interval narrows down with decreasing final temperature (e.g. $5.4 \geq$ $\mathrm{La} / \mathrm{W} \geq 5.2$ at $1300{ }^{\circ} \mathrm{C}$ ).

\section{The crystal structure of lanthanum tungstate}

Reports indexing X-ray diffraction patterns of the tungstates with larger lanthanide cations have existed since the 60s and $70 \mathrm{~s}^{6,7,20-23}$ but these studies did not present complete structural details (e.g. atomic positions). One of the inconsistencies with the traditionally written formula $\mathrm{La}_{6} \mathrm{WO}_{12}$ realized recently ${ }^{13}$ was the density of the material. The density of single-phased powders was measured by He-pycnometry to be essentially independent of the composition and equal to $\sim 6.3-6.4 \mathrm{~g} \mathrm{~cm}^{-3}$ (see Table 2$).{ }^{13}$ With the stoichiometry " $\mathrm{La}_{6} \mathrm{WO}_{12}$ " $(Z=4$, i.e.
Table 2 List of the measured density by He-pycnometry as a function of the nominal and measured La/W ratio. The error on the La/W ratio is calculated from the standard deviation of 10 measurements multiplied by 2 . The La/W ratio is measured by electron probe microanalysis on specimens sintered at $1500{ }^{\circ} \mathrm{C}$, except LWO60, sintered at $1600{ }^{\circ} \mathrm{C}$. The higher error in composition for LWO60 likely reflects segregation of phases

\begin{tabular}{llllll}
\hline Acronym & LWO53 & LWO54 & LWO56 & LWO57 & LWO60 \\
\hline La/W nominal & 5.3 & 5.4 & 5.6 & 5.7 & 6.0 \\
La/W EPMA & 5.30 & 5.45 & 5.68 & 5.75 & 6.01 \\
$2 \sigma_{\text {st }}(95 \%)$ & 0.10 & 0.07 & 0.08 & 0.07 & 0.17 \\
Density $\left(\mathrm{g} \mathrm{cm}^{-3}\right)$ & 6.38 & 6.34 & - & 6.43 & -
\end{tabular}

$\left.\mathrm{La}_{24} \mathrm{~W}_{4} \mathrm{O}_{48}\right)$ and the cell parameter $(a \sim 11.19 \AA)$, the density can be calculated to be $5.75 \mathrm{~g} \mathrm{~cm}^{-3}$. This is significantly lower than the experimental density, and unequivocally implies that the unit cell contains more ions than 24 lanthanum, 4 tungsten and 48 oxygen. Taking the cation content of a cell into account, a structural model for lanthanum tungstate was put forward using the space group $F \overline{4} 3 m^{13}$ where lanthanum occupies 2 different Wyckoff positions, La1 and La2. La1 resides in $4 \mathrm{a}(0,0$, $0)$ sites, with full occupancy, while La2 sits on $24 \mathrm{f}(1 / 4,1 / 4,1 / 4)$ positions, close to full occupancy. Tungsten is in position $4 \mathrm{~b}(1 /$ $2,1 / 2,1 / 2)$. All the oxygen is placed in 16e sites $(x, x, x)$ with $x \sim$ 0.13 and $x \sim 0.87$. A follow up study suggested that X-ray and neutron powder diffraction data can be indexed using either $F \overline{4} 3 m$ or $F m \overline{3} m$ cubic cells, with only minor differences between the two. ${ }^{18}$ It is important to emphasize that the thermal factors for $\mathrm{La} 2$ and $\mathrm{O} 2$ were quite high using both these models, which indicated disorder in the respective sublattices.

Later high resolution X-ray synchrotron studies ${ }^{19}$ revealed a very small distortion from the cubic cell, below the detection limit of a conventional laboratory X-ray diffractometer. Anyhow, the synchrotron data confirmed the atomic positions of the structural model (La1 in 4a, La2 in 24f, W1 in 4b, and O1-O2 in 16 e sites) reported in ref. 13. The stoichiometry in this case (and also when using $F \overline{4} 3 m$ or $F m \overline{3} m$ s.g.) would render $\mathrm{La}_{28} \mathrm{~W}_{4} \mathrm{O}_{54}$ $(\mathrm{La} / \mathrm{W}=7)$, which leads to a $\mathrm{La} / \mathrm{W}$ ratio higher than the one measured experimentally (La/W $\sim 5.3-5.7)$. Consequently, other tungsten positions must exist in the structure. Density Functional Theory (DFT) predicted that W dissolves in La2 sites, ${ }^{19}$ locating the "additional" tungsten. The atomic arrangements of two "ideal" compositions from DFT calculations, $\mathrm{La}_{28-x} \mathrm{~W}_{4+x} \mathrm{O}_{54+\delta} \mathrm{V}_{2-\delta}$ for $x=0$ and 1 , are shown in Fig. 3. These correspond to $\mathrm{La}_{28} \mathrm{~W}_{4} \mathrm{O}_{54} \mathrm{v}_{2}(\mathrm{La} / \mathrm{W}=7, \mathrm{LWO} 70, x=0)$ and $\mathrm{La}_{27} \mathrm{~W}_{5} \mathrm{O}_{55.5} \mathrm{~V}_{0.5}(\mathrm{La} / \mathrm{W}=5.4$, LWO54, $x=1)$. From the models shown in Fig. 3, it is clear that the structure of lanthanum tungstate on the local scale is complex. There is disorder on the oxygen sublattice ${ }^{18}$ and static disorder on the La2 site. ${ }^{24}$ The disorder rationalizes the high and anisotropic thermal factors of the $\mathrm{O} 2$ and La2 sites mentioned previously.

Further insight of the local atomic arrangements in lanthanum tungstate (LWO54) has been obtained from the combination of atomic pair distribution function analysis (PDF) of time-of-flight neutron and synchrotron X-ray data with the models from DFT. ${ }^{25}$ These experimental data verified the 

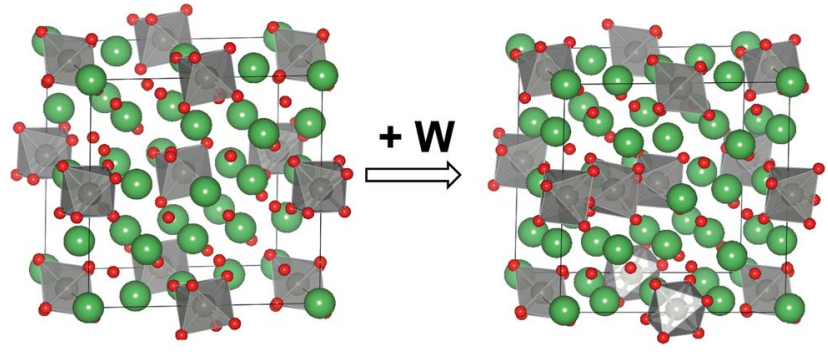

Fig. 3 Schematic representation of the local crystal structure of lanthanum tungstate. Left: $\mathrm{La}_{28} \mathrm{~W}_{4} \mathrm{O}_{54} \mathrm{~V}_{2}$ ("stoichiometric" composition, not stable). Right: $\mathrm{La}_{27} \mathrm{~W}_{5} \mathrm{O}_{55.5} \mathrm{~V}_{0.5}$ (one tungsten dissolves in La2(24g) sites to form a stable composition). Reproduced from ref. 19 with permission from the Royal Society of Chemistry.

presence of $\mathrm{W}$ on the La2 site as suggested from DFT (Fig. 3) ${ }^{19}$ and revealed that these calculations led to a plausible model to describe the experimental data of this complex oxide. Another work elucidated a local model combining synchrotron X-ray PDF analysis and EXAFS. ${ }^{24}$ They reported that the structure of LWO54 can be described by an average model (cubic fluorite supercell; space group $\mathrm{Pa} \overline{3}$ ) with disorder in the oxygen and La2 sublattice. To describe the static disorder of the La2 site, the authors in ref. 24 use the space group $P a \overline{3}$ (instead of $F \overline{4} 3 m$ or $F m \overline{3} \mathrm{~m}$ ). Nevertheless, these two final models from ref. 24 and 25 are in good agreement with each other. It is important to highlight that the latter ${ }^{24}$ detected experimentally $\sim 4.4 \%$ of anti-site disorder on the La2 site, thus confirming the dissolution of $\mathrm{W}$ on La2 sites predicted previously from DFT calculations (1/24: $4.2 \%) .^{19,25}$

One important outcome of the structural model presented in Fig. 3 is the overall stoichiometry: $\mathrm{La}_{28-x} \mathrm{~W}_{4+x} \mathrm{O}_{54+\delta} \mathrm{v}_{2-\delta}(\delta=3 x /$ 2). From this formula, it is straightforward to deduce the variation in the number of oxygen vacancies with the lanthanum-totungsten ratio and some examples are given in Table 3. There are 2 vacancies per formula unit in the "stoichiometric" composition (LWO70). However, to reduce the number of vacancies to about $1 / 2$ per unit cell and stabilize the structure, approximately one $\mathrm{W}$ is accommodated in La2 sites per formula unit as a donor dopant, $W_{\mathrm{La}}^{\cdots}$. LWO54 is accordingly a stable composition. ${ }^{19}$ In other words, lanthanum tungstate is a nominally undoped material with an inherently deficient oxygen sublattice where the concentration of vacancies depends directly on the $\mathrm{La} / \mathrm{W}$ ratio (and the final sintering temperature) (see Table 3). This can be related to the phase diagram shown in Fig. 1b: the temperature dependence of the LWO phase likely reflects the temperature dependence of the solubility of $\mathrm{W}$ in the La2 site.
There is one example in the literature that reports a stable composition with a cation ratio of 7-to-1 that is comparable to the lanthanum tungstate: $\mathrm{Y}_{7} \mathrm{ReO}_{14-\delta}$ (with $\delta \sim 0 ; \mathrm{Y}_{28} \mathrm{Re}_{4} \mathrm{O}_{56} \mathrm{~V}_{\sim 0}$ ). ${ }^{26}$ The main difference between $\mathrm{La}_{28} \mathrm{~W}_{4} \mathrm{O}_{54} \mathrm{~V}_{2}$ and $\mathrm{Y}_{28} \mathrm{Re}_{4} \mathrm{O}_{56} \mathrm{~V}_{\sim 0}$ is the vacancy concentration, related to the oxidation state of $\mathrm{W}(\mathrm{vI})$ and $\mathrm{Re}(\mathrm{VII})$. Rhenium will most probably not dissolve in yttrium sites because there are no more vacancies which can compensate a possible donor in the lattice, while tungsten dissolves in La2 sites to reduce the vacancy concentration from 2 to $\sim 1 / 2$ per unit cell.

\section{The compositional stability of LWO}

Fig. 4 shows the variation of the electrical conductivity for different lanthanum tungstates with time at $1100{ }^{\circ} \mathrm{C}$ in wet $\mathrm{H}_{2}$; for LWO53 and LWO54 the conductivity remains essentially constant and stable, while it degrades rapidly for LWO56 and LWO57. This behavior may be rationalized by the thermodynamic stability of the phase (Fig. 1b). At $1100{ }^{\circ} \mathrm{C}$, the diagram shows that LWO54 and LWO53 are single phase materials, while LWO56 and LWO57 are not. Although LWO56 and LWO57 are single phase after sintering $\left(1500{ }^{\circ} \mathrm{C}\right)$, the cations will reorganize at lower temperatures toward the stable composition with a lower $\mathrm{La} / \mathrm{W}$ ratio and therefore $\mathrm{La}_{2} \mathrm{O}_{3}$ is segregated at $1100{ }^{\circ} \mathrm{C}$. One could, in principle, expect that the conductivity of LWO57/LWO56 levels off at the same value as LWO54, but it continues to decrease. This may be associated with the formation of $\mathrm{La}_{2} \mathrm{O}_{3}$, possibly segregating to the grain boundaries, decreasing the total conductivity.

To further elucidate the origin of this degradation in electrical conductivity, the dependence of the conductivity on $\mathrm{pO}_{2}$ at $1000{ }^{\circ} \mathrm{C}$ for LWO53 and LWO57 was determined before and after long term annealing at $1100{ }^{\circ} \mathrm{C}$ (Fig. 5); the LWO53 data is

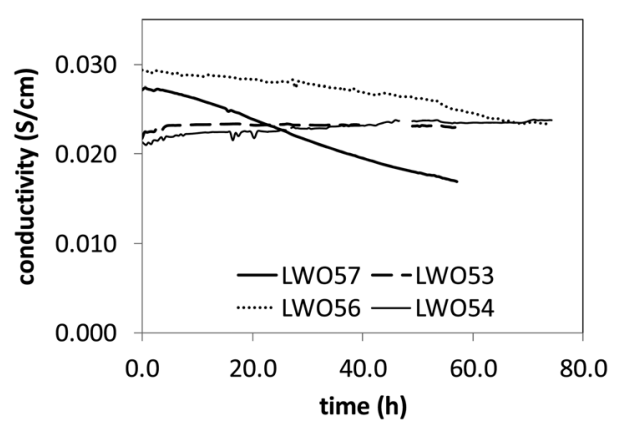

Fig. 4 Dependence of the conductivity of different tungstates at 1100 ${ }^{\circ} \mathrm{C}$ under wet $\mathrm{H}_{2}$.

Table 3 Summary of the theoretical number of vacancies and tungsten on $\mathrm{La}(24 \mathrm{~g})$ sites $(x)$ as a function of La/W ratio, based on the formula $\mathrm{La}_{28-x} \mathrm{~W}_{4+x} \mathrm{O}_{54+\delta} \mathrm{V}_{2-\delta}(\delta=3 x / 2)$

\begin{tabular}{|c|c|c|c|c|c|c|c|c|}
\hline Acronym & LWO50 & LWO52 & LWO53 & LWO54 & LWO56 & LWO57 & LWO60 & LWO70 \\
\hline La/W nominal & 5.0 & 5.2 & 5.3 & 5.4 & 5.6 & 5.7 & 6.0 & 7.0 \\
\hline$x\left(W_{\mathrm{La}}^{\cdots}\right)$ & 1.33 & 1.16 & 1.08 & 1 & 0.85 & 0.78 & 0.57 & 0 \\
\hline $\mathrm{v}$ & 0 & 0.26 & 0.38 & 0.5 & 0.73 & 0.84 & 1.14 & 2 \\
\hline Single phase? (at $1500{ }^{\circ} \mathrm{C}$ ) & No & No & Yes & Yes & Yes & Yes & No & $\mathrm{n} / \mathrm{a}$ \\
\hline
\end{tabular}


unaltered, while for LWO57 the heat treatment induces a significant decrease in the ionic, $p \mathrm{O}_{2}$ independent plateau in conductivity at intermediate oxygen pressures. XRD confirmed that $\mathrm{La}_{2} \mathrm{O}_{3}$ segregations can be found after the conductivity measurements shown in Fig. 4 for LWO57/LWO56, while these are absent for LWO54/LWO53 (Fig. 6). The lattice parameter of the nominal LWO56 decreases from $11.187 \AA$ to $11.175 \AA$ (in accordance with the latter being richer in tungsten $c f$., Fig. 2), whereas the lattice parameter of LWO54 remains essentially constant before and after the treatment (11.176 ̊̊ and 11.178 $\mathrm{A}$, respectively). These gradual changes encountered for the LWO56 and LWO57 with time altogether reflect the relative increase in the number of $\mathrm{W}$ donors at the La2 site followed by a decrease in the oxygen vacancy concentration. This behavior is attributed to the higher stability of the crystal structure with low concentration of vacancies at lower temperatures. There is, therefore, a trade-off between high ionic conductivity and stability where LWO54 probably is the best compromise.

It is worth to mention that there is no visible effect of the La/ $\mathrm{W}$ ratio on the microstructure of the materials. ${ }^{13}$ The average grain size of powders prepared from freeze-dried precursors

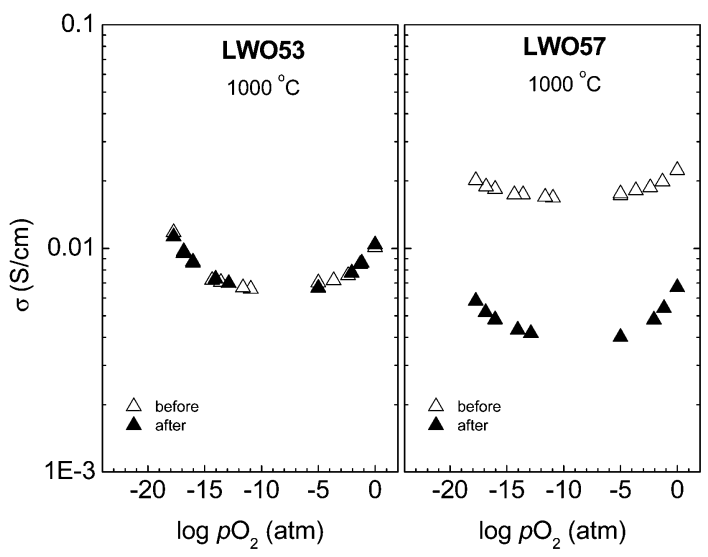

Fig. 5 Variation of the total conductivity as a function of oxygen partial pressure at $1000^{\circ} \mathrm{C}$ before and after a thermal treatment in wet $\mathrm{H}_{2}$ at $1100^{\circ} \mathrm{C}$ during 60 hours. increases from $1-3 \mu \mathrm{m}\left(1400{ }^{\circ} \mathrm{C}\right), 3-10 \mu \mathrm{m}\left(1500{ }^{\circ} \mathrm{C}\right)$ to $10-30 \mu \mathrm{m}$ $\left(1600{ }^{\circ} \mathrm{C}\right)$ independent of the composition. The densification properties and variation of the particle size of the different LWO compositions do not differ significantly, even for those containing segregations of either La- or W-rich phases. ${ }^{13}$

\section{Defect structure in LWO and hydration thermodynamics}

The effect of oxygen partial pressure on the electrical conductivity of LWO for various La/W ratios is shown in Fig. 7. The flat regime at intermediate oxygen partial pressures represents ionic conductivity, while the contributions at either side represent $\mathrm{n}$ - and p-type electronic conductivities, in accordance with previous studies. ${ }^{27,28}$ The overall conductivity behavior of LWO56, LWO57 and LWO60 is rather similar. This reflects that the level of lanthanum in the structure is saturated and therefore the maximum number of vacancies has been reached. It is evident that below $\mathrm{La} / \mathrm{W}=5.6$, the ionic conductivity decreases monotonically with decreasing $\mathrm{La} / \mathrm{W}$ ratios (see the $p \mathrm{O}_{2}$ independent plateau in Fig. 7), and is roughly proportional to the concentration of vacancies according to $\mathrm{La}_{28-x} \mathrm{~W}_{4+x} \mathrm{O}_{54+\delta} \mathrm{V}_{2-\delta}$. This is further illustrated in Fig. 8 displaying the ionic conductivity at $800{ }^{\circ} \mathrm{C}$. The difference in ionic conductivity between LWO56 and LWO52 is approximately one order of magnitude, as shown by the temperature dependence in wet $\mathrm{Ar}$ (Fig. 9). Overall, this behavior supports the hypothesis that $\mathrm{W}$ on the La site $(x)$ acts as a donor, $W_{\mathrm{La}}^{\cdots}$, and is mainly compensated by oxide ions filling up the oxygen vacancies (v). Consequently, tungsten reduces the ionic conductivity due to a decrease in the concentration of oxygen vacancies, as reported by Erdal et al. ${ }^{29}$ The positive donors also increase the concentration of electrons, which rationalizes the somewhat higher relative contribution of n-type conductivity in LWO53 than in LWO57. Electrons remain in minority concentration-wise, but with higher mobility they still have a tangible effect on the total conductivity. The ionic conductivity in LWO has been calculated based on the defect model described in ref. 30, using the concentration of vacancies from Table 3 for each LWO

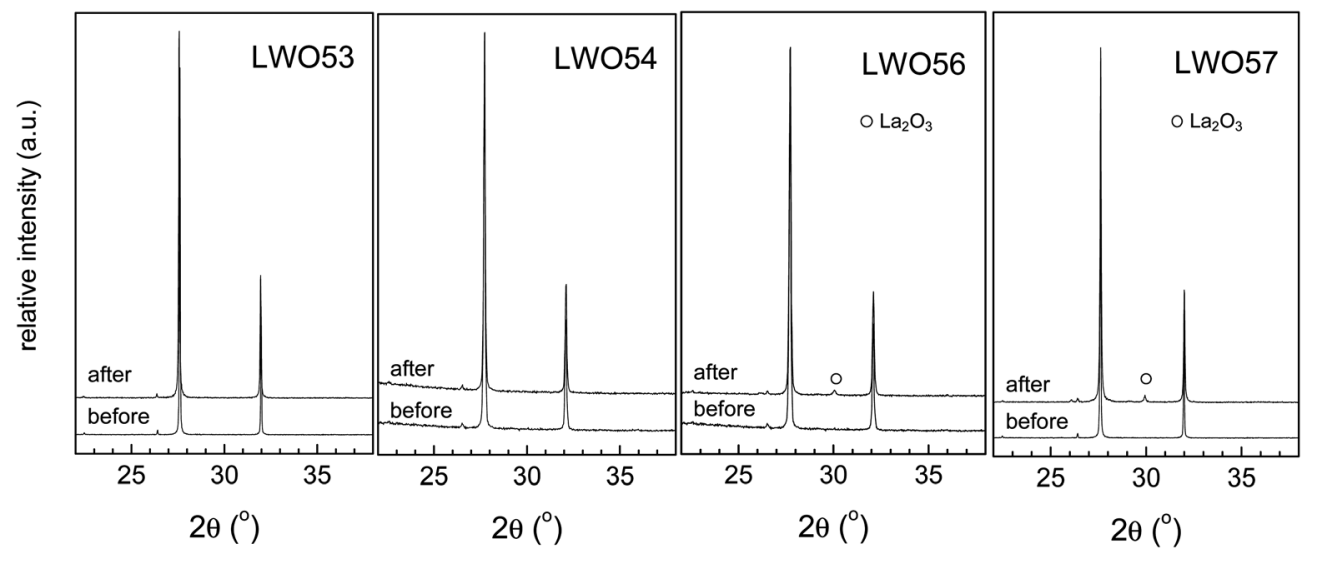

Fig. 6 X-ray diffractograms of various LWO compositions before and after long term annealing under reducing conditions at $1100{ }^{\circ} \mathrm{C}$. 


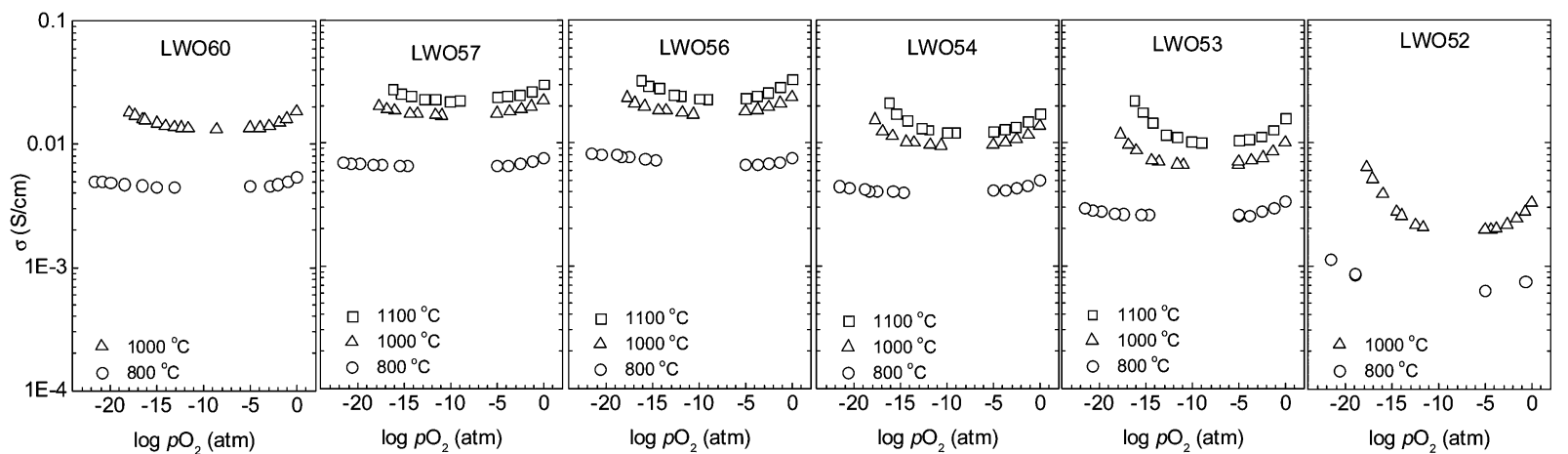

Fig. 7 2Variation of the total conductivity as a function of oxygen partial pressure at different temperatures from wet $\mathrm{H}_{2}$ to wet $\mathrm{O}_{2}$ for decreasing lanthanum content (from left to right) in LWO. All specimens were prepared using the freeze-drying method, ${ }^{13}$ except LWO60, prepared by solid state chemistry, taken from ref. 28. Conductivity data is taken from ref. 28 (LWO60) and ref. 29 (for LWO57, LWO54 and LWO53). Additional compositions were measured in parallel experiments.

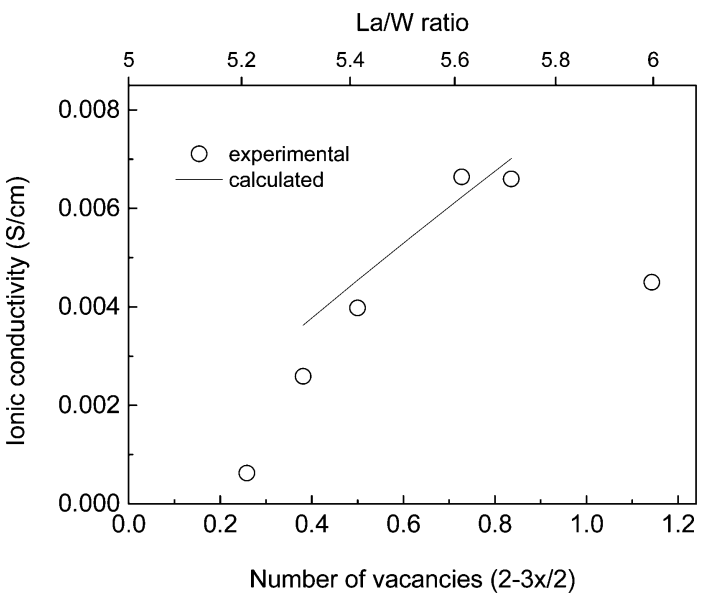

Fig. 8 Variation of the experimental ionic conductivity at $800^{\circ} \mathrm{C}$ (from Fig. 7) as a function of nominal amount of vacancies in $\mathrm{La}_{28-x} \mathrm{~W}_{4+x} \mathrm{O}_{54+\delta} \mathrm{v}_{2-\delta}$ (Table 3), compared to calculated ionic conductivity from the model described in ref. 30 .

composition within the single phase region. The calculated conductivities at $800{ }^{\circ} \mathrm{C}$ are in accordance with the experimental ones ( $c f$., Fig. 8), supporting the present defect model.

The effect of water vapour partial pressure $\left(p \mathrm{H}_{2} \mathrm{O}\right)$ at constant $\mathrm{pO}_{2}$ on the conductivity of LWO57 and LWO53 is shown in Fig. 10. The conductivity increases with increasing $p \mathrm{H}_{2} \mathrm{O}$, and the functional dependence increases with decreasing temperature. This reflects that the concentration of protons and, accordingly, their contribution to the total conductivity, increases with decreasing temperature and increasing water vapor pressure, in accordance with the exothermic hydration reaction:

$$
\mathrm{H}_{2} \mathrm{O}+\ddot{\mathrm{v}_{\mathrm{O}}}+\mathrm{O}_{\mathrm{O}}^{\times}=2 \mathrm{OH}_{\mathrm{O}}
$$

This reaction is, however, only strictly correct for materials with doubly charged oxygen vacancies, which is typically the result of acceptor doping. LWO, on the other hand, has inherent vacancies with partial occupancy. Norby ${ }^{31}$ has derived a KrögerVink compatible notation for defects in inherently defective

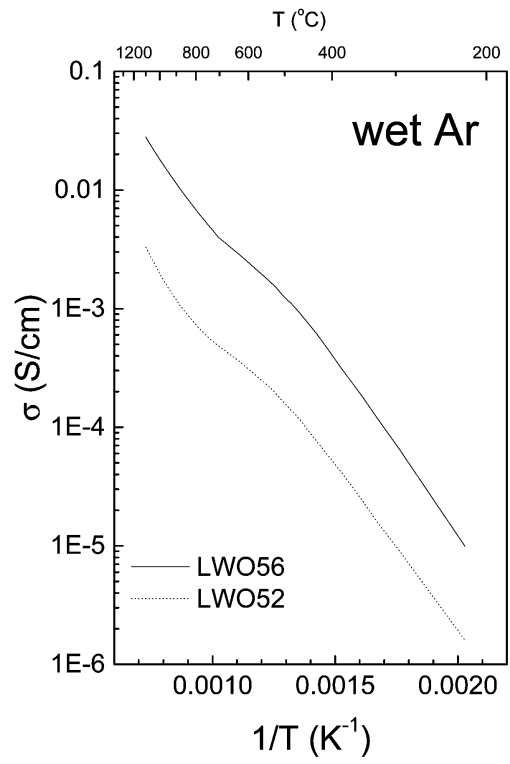

Fig. 9 Temperature dependency of the conductivity from 1100 to $\sim 200^{\circ} \mathrm{C}$ in wet Ar for LWO56 and LWO52. It mainly reflects ionic conductivity (oxide ion + protonic). Data recorded in parallel with experiments from ref. 29.

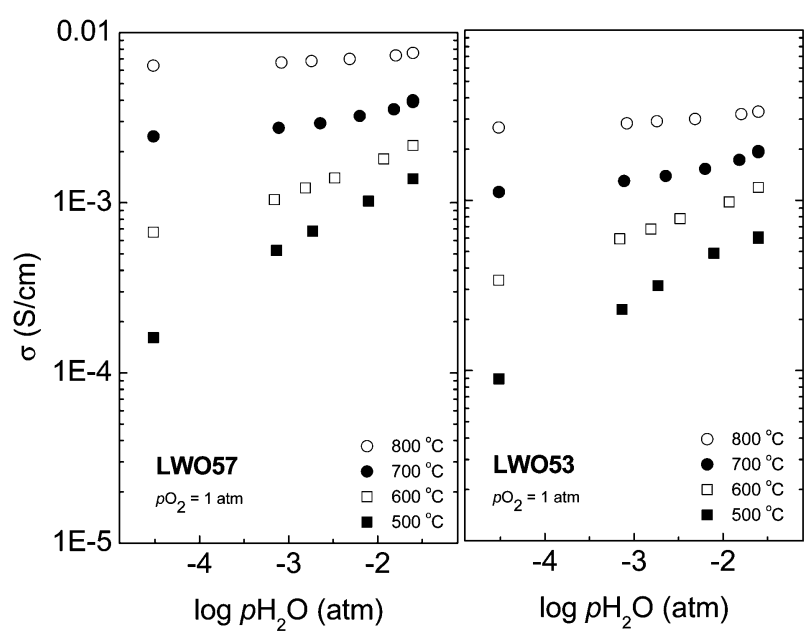

Fig. 10 Variation of the total conductivity as a function of water vapour partial pressure in $\mathrm{O}_{2}$ at different temperatures from 500 to $800{ }^{\circ} \mathrm{C}$ for LWO57 (ref. 41) and LWO53. 
sublattices, and Erdal et al. ${ }^{29}$ applied this approach to LWO. Hydration of $\mathrm{La}_{28-x} \mathrm{~W}_{4+x} \mathrm{O}_{54+\delta} \mathrm{v}_{2-\delta}$ can accordingly be written as follows:

$$
\mathrm{H}_{2} \mathrm{O}(\mathrm{g})+\mathrm{O}_{\frac{54}{56} \mathrm{O}}^{\frac{4}{56^{\prime}}}+\mathrm{v}_{\frac{54}{56} \mathrm{O}}^{\frac{108 \cdot}{56}}=2 \mathrm{OH}_{\frac{54}{56} \mathrm{O}}^{\frac{52}{56}}
$$

and the electroneutrality condition is expressed as follows:

$$
3\left[W_{\mathrm{La}}^{\cdots \cdots}\right]+\frac{108}{56}\left[\begin{array}{c}
\frac{108 \cdot}{\mathrm{V}_{54}^{66}} \\
\frac{6}{56} \mathrm{O}
\end{array}\right]+\frac{52}{56}\left[\mathrm{OH}_{\frac{54}{56} \mathrm{O}}^{\frac{55 \cdot}{56}}\right]=\frac{4}{56}\left[\mathrm{O}_{\frac{54}{56} \mathrm{O}}^{\frac{4}{56}}\right]
$$

The reader is referred to ref. 29 and 31 for details on the derivation. From this model, the hydration and the ionic conduction can be rationalized. The effective charges of the vacancies $(\sim 1.93)$ and the protons $(\sim 0.93)$ are very close to those of a standard acceptor-doped system ( 2 and 1, respectively), so lanthanum tungstate behaves, in practice, as if it was effectively acceptor doped. As outlined above, electrons and electron holes are not significant concentration-wise in the present experimental window and contribute to the conductivity of lanthanum tungstate as minority defects (at relatively high temperatures) only. The simplified electroneutrality condition (eqn (3)) accordingly takes only ionic defects into account.

Now comparing the behaviour of the different tungstates shown in Fig. 10, we observe that there is essentially no difference in the water vapor dependency of the conductivity of LWO57 and LWO53, which confirms that the defect chemical model is the same for both materials. The conductivity of LWO57 is higher than LWO53, as expected from the higher vacancy concentration in the dry state and the higher concentration of protons upon hydration at intermediate and low temperatures. The conductivity is close to being proportional to $\mathrm{pH}_{2} \mathrm{O}^{1 / 3}$ at the lowest temperature, which was initially speculated to be related to the hydration of oxygen interstitials in LWO. ${ }^{28,32}$ Later investigations of the hydration of lanthanum tungstate by means of thermogravimetry ${ }^{33}$ revealed that the dependency of the proton concentration is essentially proportional to $p \mathrm{H}_{2} \mathrm{O}^{1 / 2}$ at relatively high temperature, in accordance with the defect chemical model from eqn (3). This behavior is typical for the exothermic hydration of oxygen vacancies generally encountered in acceptor doped systems and shows that LWO indeed behaves as though it was nominally acceptor doped. From the TG data, one finds that LWO53 hydrates up to a level corresponding to the oxygen vacancy content from Table 3 , in line with the crystal structure derived by Magrasó et al. ${ }^{19}$ LWO56, however, hydrates only $66 \%$ of the nominal vacancies. There are several possible reasons for this discrepancy: as demonstrated previously in this contribution, compositions with high lanthanum contents are thermodynamically unstable at lower temperatures (typically below $1200^{\circ} \mathrm{C}$ ), forming LWO54 and $\mathrm{L}_{2} \mathrm{O}_{3}$ secondary phase. As part of this process, the number of oxygen vacancies potentially available for hydration decreases. Consequently, the maximum level of hydration for LWO56 will be sensitive to thermal history and treatments like the drying procedure at $1000-1100{ }^{\circ} \mathrm{C}$ performed in ref. 33 before the actual hydration experiment. In this respect, it is interesting to note that the maximum level of hydration reached for LWO56 corresponds essentially to a fully hydrated LWO54 composition. ${ }^{33}$ An alternative interpretation to the low hydration level in the LWO56 composition that cannot be entirely ruled out is that vacancy ordering in the compositions with higher vacancy concentration shown by $\mathrm{TEM}^{19}$ may inhibit hydration in LWO56.

\section{Effects of A-site doping in LWO Iso-valent substitution}

Haugsrud $^{28}$ reported that the protonic conductivity of a series of tungstates " $\mathrm{Ln}_{6} \mathrm{WO}_{12}$ " decreases in the order $\mathrm{La}>\mathrm{Nd}>\mathrm{Gd}>\mathrm{Er}$, likely related to a decrease in crystal symmetry towards the smaller rare-earth elements. ${ }^{5}$ The conductivity of all these materials is dominated by protons under wet atmospheres below $900^{\circ} \mathrm{C}$. The maximum in proton conductivity is observed for nominally undoped " $\mathrm{La}_{6} \mathrm{WO}_{12}$ " on the order of $3-5 \times 10^{-3} \mathrm{~S}$ $\mathrm{cm}^{-1}$. " $\mathrm{Nd}_{6} \mathrm{WO}_{12}$ " exhibits higher p-type conductivity and lower protonic conductivity compared to the lanthanum counterpart. Escolástico et al..$^{34}$ reported later that the protonic conductivity of La-substituted " $\mathrm{Nd}_{6} \mathrm{WO}_{12}$ " is higher for the composition with more La, in line with the studies by Haugsrud. ${ }^{28}$ Partial substitution of $\mathrm{Y}$ by $\mathrm{La}^{16}$ lowered the overall electrical conductivity. The effect of $\mathrm{Y}$ is likely related to a decrease in crystal symmetry and to an ordering of the vacancies in the lattice as reported by Diot et al., ${ }^{35}$ reducing the mobility of protons and oxygen vacancies.

\section{Donor-doping}

Shimura et al. ${ }^{27}$ showed that partial substitution of $\mathrm{Zr}$ for $\mathrm{La}$ decreases the conductivity. $\mathrm{Zr}$ is probably substituting lanthanum, acting as a donor dopant $\left(\mathrm{Zr}_{\mathrm{La}}\right)$, reducing the concentration of vacancies, and therefore, the ionic conductivity. Similarly, another study ${ }^{36}$ showed that when Ce was replaced by La, the ionic conductivity decreased with increasing cerium content, accompanied by a slight increase in the electronic conductivity under reducing conditions, both demonstrating the donor effect.

\section{Acceptor-doping}

Haugsrud $^{28,32}$ also reported that acceptor doping decreased the ionic conductivity for LWO60 when lanthanum was substituted by calcium ( 0.5 and $5 \%)$. This was unexpected, and initially speculated to reflect that acceptor substitution decreased the number of protons incorporated, or slowed down their mobility. It was suggested that the acceptor $\left(\mathrm{Ca}^{2+}\right)$ traps protons based on the observation that the apparent enthalpy of proton mobility increased upon acceptor doping. The effect of Ba doping also proved to decrease the overall conductivity. ${ }^{37}$ In this case, impedance spectroscopy showed that the grain boundaries were orders of magnitude more resistive than the bulk.

Later studies report that there is no detectable difference, neither in conductivity nor in the crystal structure between LWO56 and $2 \%$ Ca-doped LWO56. ${ }^{18}$ In the present contribution, we report that the conductivity actually depends on the 


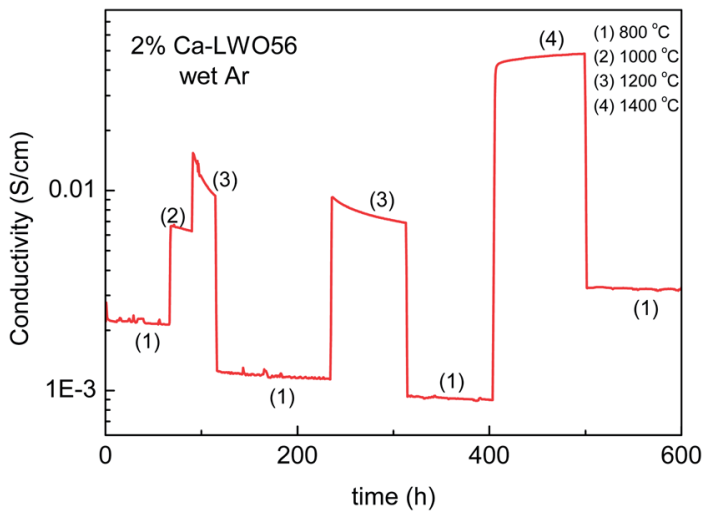

Fig. 11 Variation of the conductivity of $2 \% \mathrm{Ca}$-LWO56 in wet Ar over time upon changes in temperature. Measurement recorded after the experiments from ref. 18 .

thermal history, illustrated here in Fig. 11, showing the effects of annealing at different temperatures for $2 \%$ Ca-doped LWO56. As evident, the conductivity remains essentially stable at $800{ }^{\circ} \mathrm{C}$ (1) in wet $\mathrm{Ar}$ (representing the ionic conductivity), but decreases over time at $1000{ }^{\circ} \mathrm{C} \mathrm{(2),} \mathrm{and} \mathrm{even} \mathrm{more} \mathrm{rapidly} \mathrm{at} 1200{ }^{\circ} \mathrm{C}(3)$. The level of the conductivity at $800{ }^{\circ} \mathrm{C}$ also decreases gradually as the annealing time at the higher temperature increases. Interestingly, however, opposite effects are encountered after annealing at temperatures as high as $1400^{\circ} \mathrm{C}$; the conductivity increases during the annealing and also the level at $800{ }^{\circ} \mathrm{C}$ is higher than the original as-sintered one. This behavior either indicates that LWO phases with different La/W ratios are stabilized (as the phase diagram shown in Fig 1b suggests) at high temperatures, or that Ca-doping is meta-stable and tends to be released at intermediate temperatures between ex-solution and (re)dissolution temperatures. It is important to emphasize that LWO has low solubility of acceptor dopants (e.g. $\mathrm{Ca}^{2+}$ and $\mathrm{Sr}^{2+}$ ), around $1 \mathrm{~mol} \%$, or less. In comparison with other systems, there are a number of ternary or higher oxides in which two cations of different valences are site disordered, and where doping has none or unexpected effects. ${ }^{38}$ In those cases, doping results only in shifting the ratio of the two disordered cations, as this may have a much lower energy cost. This is accompanied by the precipitation of a phase or domains rich in the released cation, as probably occurs in our case.

Overall, A-site doping in LWO has, so far, been unsuccessful to enhance the conducting properties of the material.

\section{Effects of B-site doping in LWO}

$\mathrm{Nb}$ substitution in LWO was reported to increase the ionic conductivity by acceptor doping on the $\mathrm{W}$-site. ${ }^{39}$ The highest conductivity was measured for $\mathrm{La}_{27} \mathrm{NbW}_{4} \mathrm{O}_{55}$ to be $0.01 \mathrm{~S} \mathrm{~cm}^{-1}$ at $800{ }^{\circ} \mathrm{C}$ in wet $\mathrm{N}_{2}$. This is slightly higher than $7 \times 10^{-3} \mathrm{~S} \mathrm{~cm}^{-1}$ (for LWO56) and $4 \times 10^{-3} \mathrm{~S} \mathrm{~cm}^{-1}$ (for LWO54) in wet Ar, at $800{ }^{\circ} \mathrm{C}$. The authors mentioned that these materials are nearly pure ionic conductors at low temperatures, with transport numbers close to $1(\sim 0.98)$ below $800{ }^{\circ} \mathrm{C}$. Replacement of $\mathrm{W}$ by Re has also been reported. ${ }^{40}$ The conductivity of undoped LWO55 is $\sim 3 \times 10^{-3} \mathrm{~S} \mathrm{~cm}^{-1}$, and it increases to $\sim 4 \times 10^{-3} \mathrm{~S}$ $\mathrm{cm}^{-1}$ at $800{ }^{\circ} \mathrm{C}$ in wet $\mathrm{H}_{2}$ when $20 \%$ Re substitutes W. The authors report that the conductivity is independent of $\mathrm{pO}_{2}$ under reducing conditions. This indicates that ionic conductivity dominates under these conditions and that rhenium probably acts as an acceptor dopant. Although both studies ${ }^{39,40}$ report effects of water vapour that indicate contribution of protons under wet conditions at intermediate temperatures, the ratio between oxide ion and protonic conductivity has not been determined for any of these substitutions. This should be studied further to evaluate the potential use of these materials in hydrogen technology applications.

Amsif et $a .^{41}$ have recently shown that the replacement of tungsten by molybdenum in lanthanum tungstate $\left[\mathrm{La}_{28-y}\left(\mathrm{~W}_{1-x} \mathrm{Mo}_{x}\right)_{4+y} \mathrm{O}_{54+\delta}\right]$ is efficient to improve the electronic conductivity substantially without altering the protonic conductivity significantly, at least up to $x=0.4$. This affirmation is based on the following experimental results: (i) the ionic conductivity is relatively independent of the Mo content up to $40 \%$ substitution, see $\mathrm{pO}_{2}$ dependencies in Fig. 12, taken from ref. 30 and 41; (ii) the ratio between proton and oxide ion
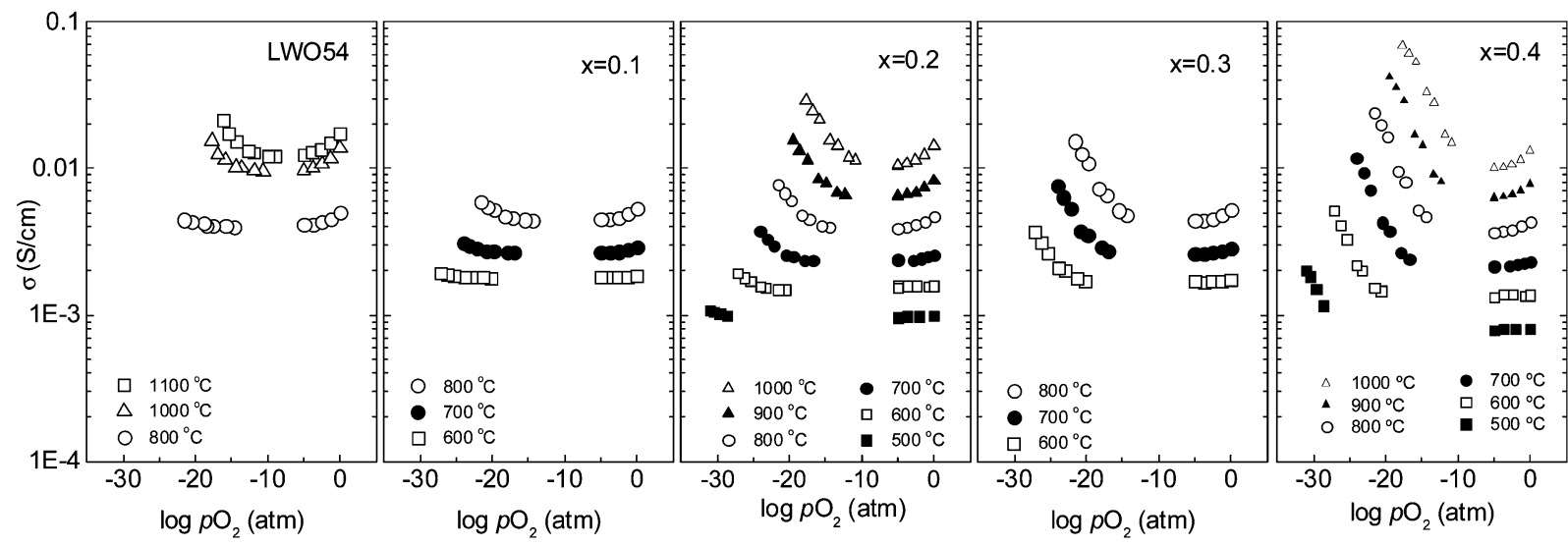

Fig. 12 Variation of the total conductivity as a function of oxygen partial pressure at different temperatures for increasing molybdenum content (from left to right), $\mathrm{La}_{28-y}\left(\mathrm{~W}_{1-x} \mathrm{Mo}_{x}\right)_{4+y} \mathrm{O}_{54+\delta}(x=0-0.4)$, taken from ref. 29,30 and 41. 


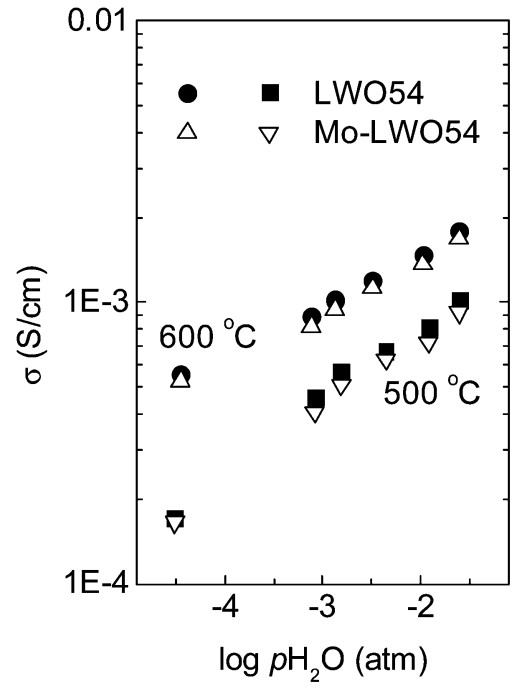

Fig. 13 Variation of the total conductivity as a function of water vapour partial pressure in $\mathrm{O}_{2}$ at 500 and $600{ }^{\circ} \mathrm{C}$ for LWO54 and $30 \%$ Mo-substituted LWO54, taken from ref. 30.

conductivity does not seem to be affected by Mo up to $40 \%$ substitution, see $p \mathrm{H}_{2} \mathrm{O}$ dependencies in ref. 30 and 41 and the comparison between Mo-free and Mo-containing compositions, shown in Fig. 13; and (iii) the partial protonic conductivities measured using the EMF method render similar values for LWO54 and 30\% Mo-substituted LWO54. ${ }^{30}$ This implies that Mo substitution in LWO results in an overall increase of the ambipolar proton-electron conductivity and thereby enhance the $\mathrm{H}_{2}$ permeation in dense ceramic membranes, as also shown by others. ${ }^{40,42}$ This is addressed in more detail in Section 7 .

All in all, B-site doping of LWO has proven to be more successful than A-site doping to enhance the conductivity of the materials. Either the ionic or electronic/ambipolar conductivity can be increased depending on the dopant.

\section{Discussion: applicability of the materials}

Lanthanum tungstate and related compositions have during the last years attracted considerable attention as electrolyte materials for proton conducting solid oxide fuel cells (PCSOFCs) and dense hydrogen gas separation membranes. ${ }^{43}$ LWO has the potential of being a suitable proton conducting electrolyte material in the range of $600-700{ }^{\circ} \mathrm{C}$, with proton conductivities in the order of $1 \mathrm{mS} \mathrm{cm} \mathrm{cm}^{-1}$. At high temperatures, LWO dehydrates, oxygen vacancies start to form at the expense of protons according to eqn (1) and (2), and oxide ion conductivity dominates over proton conductivity above $\sim 750{ }^{\circ} \mathrm{C} . .^{28,30}$ Therefore, LWO-based PC-SOFCs should operate up to temperatures of about $600{ }^{\circ} \mathrm{C}$, where the electrolyte membrane behaves as a pure proton conductor. Fuel cell testing with $\sim 1$ $\mathrm{mm}$ thick electrolyte and Pt electrodes has confirmed that LWO is predominantly an ionic conductor. The mediocre power output achieved,,$^{30}$ however, shows that thin electrolytes $(\sim 1$ $\mu \mathrm{m})$ with tailor-made electrodes are required to make LWObased PC-SOFCs competitive. NiO is not chemically compatible with $\mathrm{LWO}^{44}$ so Ni-cermet-supports with in situ reduction of sintered NiO-LWO composites are not viable. Serra and coworkers ${ }^{44,45}$ tested $\mathrm{LaCrO}_{3}$-based materials as anodes. The best performance was achieved when $\mathrm{La}_{0.75} \mathrm{Ce}_{0.1} \mathrm{Sr}_{0.15} \mathrm{CrO}_{3-\delta}$ was infiltrated with nickel nanoparticles. The overall ASR for this system was $0.3 \Omega \mathrm{cm}^{2}$ at $750{ }^{\circ} \mathrm{C}$ in wet $\mathrm{H}_{2}$. LWO is chemically and mechanically stable with LSM $\left(\mathrm{La}_{0.7} \mathrm{Sr}_{0.3} \mathrm{MnO}_{3-\delta}\right)$ and LSCM $\left(\mathrm{La}_{0.75} \mathrm{Sr}_{0.25} \mathrm{Cr}_{0.5} \mathrm{Mn}_{0.5} \mathrm{O}_{3-\delta}\right){ }^{46}$ but relatively high ASRs were measured 3-4 $\Omega \mathrm{cm}^{2}$ in wet air at $750{ }^{\circ} \mathrm{C}$ for LSM-based cathodes. ${ }^{46,47}$ Optimized $50 \% \mathrm{Pr}_{2} \mathrm{NiO}_{4}-50 \%$ LWO composites show ASR values of only $0.5 \Omega \mathrm{cm}^{2}$ at $700{ }^{\circ} \mathrm{C}$, as such being a promising cathode candidate for use in PC-SOFCs. ${ }^{48}$

Focus onwards will be on the regime where LWO is a mixed proton-electron conductor. There is an increasing number of reports on the hydrogen flux in membranes of LWO-based materials, and the potential as a hydrogen permeable membrane has thus been demonstrated. For unsubstituted LWO, the electronic conductivity is relatively low at $T<800{ }^{\circ} \mathrm{C}$, and the $\mathrm{H}_{2}$ permeation via ambipolar transport of protons and electrons is low at these temperatures. Even up to $\sim 950$ to $1000{ }^{\circ} \mathrm{C}$, the hydrogen flux is limited by n-type electronic conductivity, whereas protons are the limiting species above this temperature due to the dehydration of the material. At $1000{ }^{\circ} \mathrm{C}$, the ambipolar proton-electron conductivity in lanthanum tungstate (LWO56) is approximately $10^{-3} \mathrm{~S} \mathrm{~cm}^{-1},{ }^{49}$ which renders hydrogen fluxes comparable to the best mixed proton-electron conducting perovskites. The hydrogen flux of LWO56 is $0.041 \mathrm{ml} \mathrm{min}{ }^{-1} \mathrm{~cm}^{-2}$ (wet $\mathrm{H}_{2}$ on the feed side), ${ }^{49}$ $0.046 \mathrm{ml} \mathrm{min}^{-1} \mathrm{~cm}^{-2}$ for Nd-substituted LWO55 (wet $\left.50 \% \mathrm{H}_{2}\right)^{34}$ or $\sim 0.08 \mathrm{ml} \mathrm{min}^{-1} \mathrm{~cm}^{-2}$ for LWO55 (wet $50 \% \mathrm{H}_{2}$ ), ${ }^{40}$ all at $1000{ }^{\circ} \mathrm{C}$ and with wet $\mathrm{Ar}$ on the permeate side. These membranes were 1-2 mm thick, and the flux can be further increased by decreasing the membrane thickness. Gil et al. ${ }^{50}$ reported that a $25-30 \mu \mathrm{m}$ LWO56 supported on a porous matrix of the same composition led to an increased hydrogen flux $\left(0.14 \mathrm{ml} \mathrm{min}^{-1} \mathrm{~cm}^{-2}\right.$ in wet $\left.10 \% \mathrm{H}_{2}-\mathrm{Ar}\right)$. This value was, however, lower than expected based on measurements for thicker membranes. The deviation may indicate that surface kinetics is limiting the flux across the thinner membrane, as also suggested by the sluggish transport kinetics in LWO56 reported by Hancke $e t$ al. ${ }^{51}$ and suggested to reflect slow surface kinetics, in line with the flux data.

It is important to highlight when discussing the application of these materials as hydrogen membranes that the level of $\mathrm{H}_{2}$ in the permeate increases dramatically when the carrier gas on the permeate side is wetted. This could, in principle, be related to a higher degree of hydration of the membrane, but it has been shown that water splitting is the main cause. ${ }^{42}$ Water splits as a consequence of the oxygen gradient from the sweep side to the feed side and the oxide ions migrate through the membrane towards the feed, leaving $\mathrm{H}_{2}$ behind at permeate side. This $\mathrm{H}_{2}$ does consequently not originate from ambipolar transport of protons and electrons from the feed side to the permeate side. This effect becomes more important at the higher temperatures, as the oxide ion conductivity increases with increasing 
temperature. Although for $\mathrm{H}_{2}$ separation purposes water splitting does not pose a problem, it is in many cases important to realize how much of the detected $\mathrm{H}_{2}$ that comes from permeation (representing actual gas separation) and how much that stems from water splitting at the permeate side (hydrogen production, not separation). It has been shown that the hydrogen flux detected when the permeate side is dry is in accordance with the value estimated from ambipolar transport of protons and electrons, ${ }^{\mathbf{4 2}}$ and can be taken as a reference to differentiate $\mathrm{H}_{2}$ separation and $\mathrm{H}_{2}$ production.

The chemical stability of LWO against $\mathrm{CO}_{2}$ has been confirmed for LWO55. ${ }^{40}$ This represents one of the main advantages of this family of materials over the previous state-ofthe-art, $\mathrm{SrCeO}_{3}$, which readily forms carbonates even in atmospheres containing small amounts of $\mathrm{CO}_{2}$. It is also interesting to highlight that LWO is more stable towards cation diffusionrelated degradation than many of the most promising oxygen transport membrane materials, since bulk diffusivities of $\mathrm{W}$ and La are very similar and relatively slow. ${ }^{52}$ The thermal expansion coefficient (TEC) for lanthanum tungstate was determined by different laboratories to be $\sim 11-12 \times 10^{-6} \mathrm{~K}^{-1}$ [ref. 18 and 53], and the expansion is isotropic since the crystal symmetry is cubic. It is important from a technological point of view that a material with a practical application exhibits a linear isotropic thermal expansion coefficient, to make thermal compatibility with the surrounding materials easier. In addition, the TEC is essentially independent of $\mathrm{pO}_{2}$ (LWO does not reduce or oxidize significantly) and only slightly dependent on $p \mathrm{H}_{2} \mathrm{O}$, due to hydration.

As mentioned previously, B-site doping strategies have been the most successful approach to increase the conductivity in LWO. The replacement of tungsten by molybdenum in lanthanum tungstate is particularly interesting, since the electronic conductivity is enhanced substantially without altering the protonic conductivity significantly. ${ }^{\mathbf{3 0 , 4 1}}$ Other authors have claimed that Mo substitution decreases protonic conductivity. ${ }^{\mathbf{4 0}}$ However, the statement was based on results from measurement of the $\mathrm{pH}_{2} \mathrm{O}$ dependency on the electrical conductivity under reducing conditions. Under these conditions electronic conductivity prevails and the relative contribution of protonic conductivity is smaller for the Mo-substituted LWO, but it does not necessarily mean that the $\sigma_{\mathrm{H}^{+}}$is smaller. The influence of electronic defects on the water vapour dependence of the conductivity can be minimized if the measurements are done under inert or oxidizing conditions, as performed in ref. 30 and 41 and shown here in Fig. 12 (all in $\mathrm{O}_{2}$ ). We should remind the reader that p-type conductivity is relatively independent of the Mo-content, ${ }^{\mathbf{4 1}}$ and quite low at the temperatures measured $\left(500-800{ }^{\circ} \mathrm{C}\right)$.

The ambipolar proton-electron conductivity

$$
\sigma_{\mathrm{amb}}=\frac{\sigma_{\mathrm{H}^{+}} \sigma_{\mathrm{e}^{\prime}}}{\sigma_{\mathrm{H}^{+}}+\sigma_{\mathrm{e}^{\prime}}}
$$

has been estimated for $\mathrm{La}_{28-y}\left(\mathrm{~W}_{1-x} \mathrm{Mo}_{x}\right)_{4+y} \mathrm{O}_{54+\delta}$ with $0 \leq x \leq$ 0.4 and $y \sim 1$ (Fig. 14). $\sigma_{\mathrm{H}^{+}}$is taken from the modeled partial proton conductivity extracted using the EMF method (and the assumed constant for $x \leq 0.4$ ), and $\sigma_{\mathrm{e}^{\prime}}$ is extracted for each composition using the $\mathrm{O}_{2}$ dependency of the conductivity from

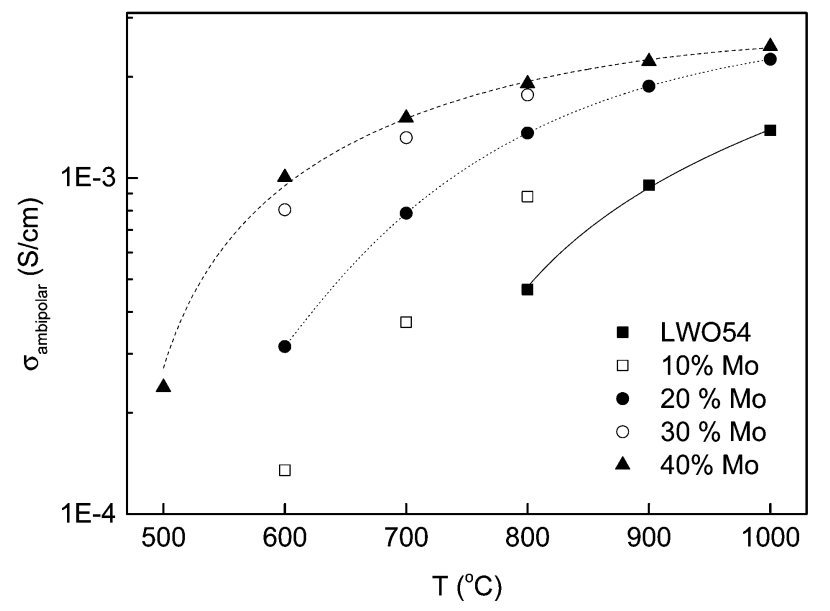

Fig. 14 Estimated ambipolar conductivities in wet $\mathrm{H}_{2}$ of undoped and Mo-substituted LWO. The partial proton conductivities are taken from those obtained using the EMF method (see ref. 30), which are assumed constant as a function of Mo doping up to $40 \%$ (the author is referred to the text to support this statement). The partial electronic conductivities are extracted from the dependency of the conductivity vs. $\mathrm{pO}_{2}$ at each indicated temperature (from ref. 30 and 41). Lines are guides to the eye, only.

Fig. 12. The ambipolar conductivity is clearly dependent on the Mo-content at all temperatures, due to the strong enhancement of electronic conductivity with increasing Mo-content. The $\sigma_{\mathrm{amb}}$ is approximately a factor of two higher at $1000{ }^{\circ} \mathrm{C}$ when $20 \%$ of the $\mathrm{W}$ is replaced by Mo. The enhancement is even more evident at the lowest temperatures: already at $\sim 650{ }^{\circ} \mathrm{C}$, the ambipolar conductivity of a $30-40 \%$ Mo substitution LWO is comparable to that obtained for LWO54 at $1000{ }^{\circ} \mathrm{C}$. This is a considerable improvement and decreases the operating temperature of hydrogen separation membranes based on LWO. One may note from Fig. 14 that the temperature dependence of $\sigma_{\mathrm{amb}}$ is steeper for LWO than that for the Mo-substituted tungstate. This reflects that the limiting species in the ambipolar conductivity change from being electrons (in LWO) to protons (in $40 \% \mathrm{Mo}-$ LWO). Recent permeation measurements comparing LWO with $30 \%$ Mo-LWO confirm this statement. ${ }^{42}$

When compared to the other state-of-the-art materials for hydrogen permeation, systems based on acceptor-doped $\mathrm{SrCeO}_{3}$ are the most studied so far, see e.g. ref. 54-58. These materials are predominantly protonic conductors below $600-700{ }^{\circ} \mathrm{C},{ }^{54}$ so that high ambipolar conductivity can only be obtained via suitable doping and/or by increasing temperature. Oh et al. ${ }^{58}$ reported that the ambipolar conductivity of $\mathrm{SrCe}_{0.85} \mathrm{Eu}_{0.15} \mathrm{O}_{3-\delta}$ was close to $10^{-3} \mathrm{~S} \mathrm{~cm}^{-1}$ at $900{ }^{\circ} \mathrm{C}$, which is comparable to that of $40 \%$ Mo-LWO at $600{ }^{\circ} \mathrm{C}$. The hydrogen flux measured for $1 \mathrm{~mm}$ thick $\mathrm{SrCe}_{0.95} \mathrm{Yb}_{0.05} \mathrm{O}_{3-\delta}$ at $677{ }^{\circ} \mathrm{C}$ is $\sim 0.007 \mathrm{ml} \mathrm{cm}{ }^{-2}$ $\min ^{-1}, 59$ or $\sim 0.05 \mathrm{ml} \mathrm{cm}{ }^{-2} \min ^{-1}$ for $0.8 \mathrm{~mm}$ thick $\mathrm{SrCe}_{0.95} \mathrm{Tm}_{0.05} \mathrm{O}_{3-\delta}$ at $950{ }^{\circ} \mathrm{C} .{ }^{60}$ The flux can increase substantially with decreasing membrane thickness, as reported for $33 \mu \mathrm{m}$ thick $\mathrm{SrCe}_{0.7} \mathrm{Zr}_{0.2} \mathrm{Eu}_{0.1} \mathrm{O}_{3-\delta}\left(0.23 \mathrm{ml} \mathrm{cm}{ }^{-2} \mathrm{~min}^{-1}\right.$ at $\left.900{ }^{\circ} \mathrm{C}\right),{ }^{61}$ and for $2 \mu \mathrm{m}$ thick $\mathrm{SrCe}_{0.95} \mathrm{Yb}_{0.05} \mathrm{O}_{3-\delta}\left(\sim 15 \mathrm{ml} \mathrm{cm}^{-2}\right.$ $\min ^{-1}$ at $\left.677{ }^{\circ} \mathrm{C}\right) .{ }^{59}$ The main drawback for a widespread application of $\mathrm{SrCeO}_{3}$-based materials is the low chemical 
stability, and the tungstates can offer a feasible alternative with substantially increased chemical stability. The $\mathrm{H}_{2}$ permeation of $5 \mu \mathrm{m}$-thick $40 \%$ Mo-substituted LWO is predicted to be $\sim 2 \mathrm{ml}$ $\mathrm{cm}^{-2} \mathrm{~min}^{-1}$ at $600{ }^{\circ} \mathrm{C}$, using a gradient of $\mathrm{pH}_{2}$ of one order of magnitude, an ambipolar conductivity of $\sim 1.6 \times 10^{-3} \mathrm{~S} \mathrm{~cm}^{-1}$, and assuming that bulk diffusion is limiting. We should emphasize, however, that surface limitations have been encountered for LWO and Mo-substituted LWO, ${ }^{42}$ and that surface treatment to increase kinetics must be taken into account in the optimization process.

All in all, Mo-substituted LWO embraces a family of truly competitive materials for $\mathrm{H}_{2}$ permeation and further development on the optimization of the cation ratio, microstructure of the membrane and surface treatment will be dealt with in the future.

\section{Acknowledgements}

The data reported and the discussion thereof summarizes work financed by Research Council of Norway (grant nos 187160, 193816, 190901, 171157, 191346, nn4604k). All the insight gained through these projects and the collaboration with all the project partners is gratefully acknowledged. In addition, thanks to Prof. Truls Norby, PhD fellows, and Post Docs, for sharing thoughts, results, and discussions.

\section{References}

1 S. F. Bartram, Inorg. Chem., 1966, 5(5), 749-754.

2 S. F. Bartram, E. F. Juenke and E. A. Aitken, J. Am. Ceram. Soc., 1964, 47, 171-175.

3 E. A. Aitken, S. F. Bartram and E. F. Juenke, Inorg. Chem., 1964, 3(7), 949-953.

4 H. J. Borchardt, Inorg. Chem., 1963, 2(1), 170-173.

5 G. J. McCarthy, R. D. Fisher, G. G. Johnson and C. E. Gooden, National Bureau of Standards Special Publication, Solid State Chemistry in Proceedings of the 5th Materials Research Symposium, 1972, p. 397.

6 L. L. Y. Chang, M. G. Scroger and B. Phillips, J. Inorg. Nucl. Chem., 1966, 28(5), 1179-1184.

7 L. L. Y. Chang and B. Phillips, Inorg. Chem., 1964, 3(12), 1792-1794.

8 M. M. Ivanova and E. M. Reznik, Izvestiya Akademii Nauk SSSR, Neorg. Mater., 1972, 8(5), 981-983.

9 M. Yoshimura and A. Rouanet, Mater. Res. Bull., 1976, 11, 151-158.

10 T. Hartmann, H. Ehrenberg, G. Miehe, G. Wltschek and H. Fuess, J. Solid State Chem., 1999, 148, 220-223.

11 D. Michel and A. Kahn, Acta Crystallogr., Sect. B: Struct. Crystallogr. Cryst. Chem., 1982, 38, 1437-1441.

12 A. P. Richard and D. D. Edwards, J. Solid State Chem., 2004, 177, 2740-2748.

13 A. Magrasó, C. Frontera, D. Marrero-López and P. Núñez, Dalton Trans., 2009, 10273-10283.

$14 \mathrm{M}$. H. Chambrier and F. Goutenoire, JEEP, EDP Sciences, 2009, p. 00022.

15 M. Yoshimura and J. F. Baumard, Mater. Res. Bull., 1975, 10(9), 983-988.
16 A. Lashtabeg, J. Bradley, A. Dicks, G. Auchterlonie and J. Drennan, J. Solid State Chem., 2010, 183(5), 10951101.

17 C. Solis, S. Escolastico, R. Haugsrud and J. M. Serra, J. Phys. Chem. C, 2011, 115, 11124-11131.

18 A. Magrasó, C. H. Hervoches, I. Ahmed, S. Hull, J. Nordström, A. W. B. Skilbred and R. Haugsrud, J. Mater. Chem. A, 2013, 1, 3774.

19 A. Magrasó, J. M. Polfus, C. Frontera, J. Canales-Vazquez, L.-E. Kalland, C. H. Hervoches, S. Erdal, R. Hancke, M. S. Islam, T. Norby and R. Haugsrud, J. Mater. Chem., 2012, 22(5), 1762-1764.

20 M. Yoshimura, F. Sibieude, A. Rouanet and M. Foex, J. Solid State Chem., 1976, 16(3-4), 219-232.

21 V. K. Trunov, G. I. Tyushevskaya and N. S. Afonskii, Zh. Neorg. Khim., 1968, 13(4), 936-939.

22 G. J. McCarthy, Mater. Res. Bull., 1971, 6(1), 31-39.

23 E. Summerville, J. Drennan and D. J. M. Bevan, J. Phys. Colloq., 1977, 38(C7), 73-79.

24 T. Scherb, S. A. J. Kimber, C. Stephan, P. F. Henry, G. Schumacher, J. Just, S. Escolastico, J. M. Serra, J. Seeger, A. H. Hill and J. Banhart, arXiv:1305.3385v1, 2013.

25 L.-E. Kalland, A. Magrasó, A. Mancini, C. Tealdi and L. Malavasi, Chem. Mater., 2013, 25(11), 2378-2384.

26 H. Ehrenberg, T. Hartmann, K. G. Bramnik, G. Miehe and H. Fuess, Solid State Sci., 2004, 6, 247-250.

27 T. Shimura, S. Fujimoto and H. Iwahara, Solid State Ionics, 2001, 143, 117-123.

28 R. Haugsrud, Solid State Ionics, 2007, 178(7), 555-560.

29 S. Erdal, L.-E. Kalland, R. Hancke, J. Polfus, R. Haugsrud, T. Norby and A. Magrasó, Int. J. Hydrogen Energy, 2012, 37(9), 8051-8055.

30 A. Magrasó, J. Power Sources, 2013, 240, 583-588.

31 T. Norby, J. Korean Ceram. Soc., 2010, 47, 19-25.

32 R. Haugsrud and C. Kjølseth, J. Phys. Chem. Solids, 2008, 69(7), 1758-1765.

33 R. Hancke, A. Magrasó, T. Norby and R. Haugsrud, Solid State Ionics, 2013, 231, 25-29.

34 S. Escolástico, C. Solís and J. M. Serra, Solid State Ionics, 2012, 216, 31-35.

35 N. Diot, P. Benard-Rocherulle and R. Marchand, Powder Diffr., 2000, 15(04), 220-226.

36 N. Alyeshkina, Defects and Transport in Ce-doped $\mathrm{La}_{27} \mathrm{~W}_{5} \mathrm{O}_{55.5}$, M.Sc. thesis, University of Oslo, 2013.

37 X. Cui, Defects and Transport in Ba-doped $\mathrm{La}_{27} \mathrm{~W}_{5} \mathrm{O}_{55.5}$, M.Sc. thesis, University of Oslo, 2013.

38 W. Xing, K. Toyoura and T. Norby, Int. J. Hydrogen Energy, 2012, 37(9), 8062-8065.

39 M. J. Zayas-Rey, L. dos Santos-Gomez, D. Marrero-Lopez, L. Leon-Reina, J. Canales-Vazquez, M. A. G. Aranda and E. R. Losilla, Chem. Mater., 2013, 25(3), 448-456.

40 S. Escolastico, J. Seeger, S. Roitsch, M. Ivanova, W. A. Meulenberg and J. Serra, ChemSusChem, 2013, 6(8), 1523-1532.

41 M. Amsif, A. Magrasó, D. Marrero-López, J. C. Ruiz-Morales, J. Canales-Vázquez and P. Núñez, Chem. Mater., 2012, 24(20), 3868-3877. 
42 E. Vøllestad, C. K. Vigen, A. Magrasó and R. Haugsrud, J. Membr. Sci., 2014, 461, 81-88.

43 R. Haugsrud, New high-temperature proton conductors for fuel cells and gas separation membranes, Handbook of Fuel Cells, 2010.

44 C. Solis, V. B. Vert, M. Balaguer, S. Escolastico, S. Roitsch and J. M. Serra, ChemSusChem, 2012, 5, 2155.

45 M. Balaguer, C. Solis, F. Bozza, N. Bonanos and J. M. Serra, J. Mater. Chem. A, 2013, 1(9), 3004-3007.

46 E. Quarez, K. V. Kravchyk and O. Joubert, Solid State Ionics, 2012, 216, 19-24.

47 C. Solís, L. Navarrete, S. Roitsch and J. M. Serra, J. Mater. Chem., 2012, 22, 16051.

48 E. Quarez, Y. Oumellal and O. Joubert, Fuel Cells, 2013, 13(1), 34-41.

49 S. Erdal, Hydrogen in Oxides: incorporation, transport and effects on electrical properties, Ph.D. thesis, University of Oslo, 2011.

50 V. Gil, J. Gurauskis, C. Kjølseth, K. Wiik and M.-A. Einarsrud, Int. J. Hydrogen Energy, 2013, 38(7), 3087-3091.

51 R. Hancke, S. Fearn, J. A. Kilner and R. Haugsrud, Phys. Chem. Chem. Phys., 2012, 14(40), 13971-13978.
52 E. Vøllestad, T. Norby and R. Haugsrud, Solid State Ionics, 2013, 244, 57-62.

53 E. Quarez, K. V. Kravchyk and O. Joubert, Solid State Ionics, 2012, 216, 19-24.

54 T. Norby and R. Haugsrud, Dense Ceramic Membranes for Hydrogen Separation. I: Nonporous Inorganic Membranes for Chemical Processing, Wiley-VCH Verlagsgesellschaft, 2006, pp. 1-48, ISBN 3-527-31342-7.

55 S.-J. Song, E. D. Wachsman, J. Rhodes, S. E. Dorris and U. Balachandran, Solid State Ionics, 2003, 164, 107-116.

56 X. Qi and Y. S. Lin, Solid State Ionics, 2000, 130, 149156.

57 G. C. Mather and M. S. Islam, Chem. Mater., 2005, 17, 17361744.

58 T. Oh, H. Yoon and E. D. Wachsman, Solid State Ionics, 2009, 180, 1233-1239.

59 S. Hamakawa, L. Li, A. Li and E. Iglesia, Solid State Ionics, 2002, 148, 71-81.

60 S. Cheng, V. K. Gupta and J. Y. S. Lin, Solid State Ionics, 2005, 176, 2653-2662.

61 J. Li, H. Yoon and E. D. Wachsman, J. Membr. Sci., 2011, 381, 126-131. 